\title{
HOLOCAUST AND HUMAN RIGHTS EDUCATION
}





\section{HOLOCAUST AND HUMAN RIGHTS EDUCATION: GOOD CHOICES AND SOCIOLOGICAL PERSPECTIVES}

BY

MICHAEL POLGAR

Penn State Hazleton, USA

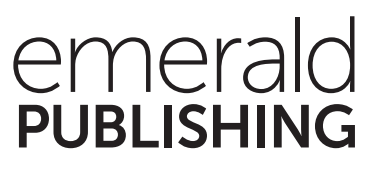

United Kingdom - North America - Japan - India - Malaysia - China 
Emerald Publishing Limited

Howard House, Wagon Lane, Bingley BD16 1WA, UK

First edition 2019

(C) 2019 Michael Polgar

Published under exclusive licence by Emerald Publishing Limited.

\section{Reprints and permissions service}

Contact: permissions@emeraldinsight.com

No part of this book may be reproduced, stored in a retrieval system, transmitted in any form or by any means electronic, mechanical, photocopying, recording or otherwise without either the prior written permission of the publisher or a licence permitting restricted copying issued in the UK by The Copyright Licensing Agency and in the USA by The Copyright Clearance Center. Any opinions expressed in the chapters are those of the authors. Whilst Emerald makes every effort to ensure the quality and accuracy of its content, Emerald makes no representation implied or otherwise, as to the chapters' suitability and application and disclaims any warranties, express or implied, to their use.

\section{British Library Cataloguing in Publication Data}

A catalogue record for this book is available from the British Library

ISBN: 978-1-78754-499-4 (Print)

ISBN: 978-1-78754-498-7 (Online)

ISBN: 978-1-78756-000-0 (Epub)

ISOQAR certified

Management System,

awarded to Emerald

for adherence to

Environmental

standard

ISOQAR ISO 14001:2004. 


\section{Table of Contents}

On Terminology vii

Preface ix

Chapter 1 Introduction 1

Chapter 2 Why We Teach Holocaust Education 11

Chapter 3 How We Teach Holocaust Education 31

Chapter 4 Realizing Our Responsibilities 55

$\begin{array}{lll}\text { Chapter } 5 & \text { Teaching Strong Cultures } & 73\end{array}$

Chapter 6 Survivors Share Resilience 95

Chapter 7 Global Holocaust Education for the Twenty-First Century 111

$\begin{array}{ll}\text { References } & 129\end{array}$

$\begin{array}{ll}\text { Index } & 147\end{array}$ 



\section{On Terminology}

The Holocaust was a 12-year historical event that is defined by the international community and the United State Holocaust Museum as "the systematic, bureaucratic, state-sponsored persecution and murder of 6 million Jews by the Nazi regime and its collaborators (United States Holocaust Memorial Museum 2018)." "Holocaust" literally means a sacrifice by fire. The Holocaust is also well described in other terms as a catastrophic event ("Shoah" or "Kurban"). In this text, therefore, catastrophe and Shoah are used in this text synonymously with "the Holocaust." In this text, the term "Holocaust" will not, and many believe should not, be used or misused as a metaphor for other destructive, violent, or catastrophic events, since doing so can dilute, distract from, or confuse learning about historical truths and consequences of the Holocaust (Novick, 1999).

Genocide is a general term for intentional efforts to destroy, in whole or in part, a national, ethnic, racial or religious group of people. After the Holocaust, the United Nations agreed that genocide is an international crime marked by mass violence (Lemkin, 1947). The Holocaust was the first, but certainly not the last or only, event that has been classified as a genocide. Therefore we will explore how Holocaust education can be (but is not always) part of genocide education.

The term Holocaust survivor is often used for those Holocaust protagonists who were directly harmed by the Holocaust, but more specifically those who were defined as such by official agencies after being held in ghettos or/and interned in concentration camps and in lands under Nazi occupation (Stein, 2014). More expansive definitions of this term include people who were harmed in other ways, including those who were forced to flee and become homeless or refugees, people robbed of possessions, and people who were deprived of ways to live or earn a living. Thus we may classify or specify survivors according to their experiences during the Holocaust, sometimes by including the names and types of camps experienced (e.g., Auschwitz survivor and author Primo Levi). "Genocide survivors" more generally describes people who endure persecution during any of many different genocides. Other important Holocaust-era protagonists include perpetrators, bystanders or onlookers, resistors, and also many groups of refugees displaced by war and conflict (Hayes \& Roth, 2010).

Testimonies from Holocaust witnesses are spoken, written, and other accounts from survivors and others who lived through the Holocaust. What gets called "testimony" can and will also be called narratives, accounts, or more fully described with the verb recounting, which more fully describes the processual nature of sharing and then retelling experiences, rather than a more formal and 
completed "witness testimonial" which is more like a response to inquiry where the narrator is reporting on a contested or uncertain situation, often in a legal setting (Greenspan, 2010a). Challenging accounts by survivors may further harm those who may already have difficulties with anguished or humiliated memories (Langer, 1991).

Survivors recount experiences in many contexts. Some narratives are simply given as presentations while others are drawn out through interviews, sometimes creating oral histories. Witness accounts can also be treated as "oral philosophies" and "oral psychologies" that help us understand the difficult consequences and sometimes traumatic memories (Greenspan, 2010a). These distinctions matter since not all narratives are simply or strictly reports on past events and also since many authors and observers seek more from survivors than a descriptive accounting of the past. With the exception of fictional accounts, survivor narratives are not often well described as stories, even though many do use this term in this context, since these are most often true. Clearly, the ugly truth of some deep, anguished, and even unheroic aspects of testimonials can be difficult for survivors to share, drudging up "the ruins of memory" (Langer, 1986, 1991). Narrative recounting of the Holocaust can also be difficult for some audiences to stomach or even to accept as real experiences.

Many other terms, particularly those for status groups, may require clarifications during Holocaust education and discussion, reinforcing the fact that educational standards promote political literacies and civic education. These include "Nazi," "Jew," and "Roma," along with "Camp" and "Ghetto" (Cowan \& Maitles, 2017). "Nazi" is a political (not strictly national) status, reflecting membership in a (German) National Socialist Party or governmental role; Nazi should and will not be used synonymously for a person who is nationally, ethnically, or culturally "German."

Educators can help students by discussing the varying definitions of "Jewish" and "Roma" in classes where these terms are not well understood. "Ghettos" during the Holocaust should and will be distinguished from this term's modern use to describe certain impoverished urban areas, while "camps" should be prefaced by a (sometimes overlapping or evolving) type or types (transit, detention, concentration, forced labor, death, POW, and DP camps). It's not easy to simply or exactly describe all of these prisons, however, since all concentrate people and many served multiple functions (Cowan \& Maitles, 2017).

Thank you for your patience with these linguistic details and specifics! While I genuinely appreciate and work to use inclusive language in general, I do not consider only one vocabulary to be "correct." At the same time, I do want my or our uses of terms and language to effectively communicate exactly what I mean. These are sensitive topics and much more oppressive and false uses of terminology were previously dictated by criminal Nazi persecutors. We communicate more effectively through best uses of key concepts and terms and best usage of our languages. We, kind readers and this author, are each both educators and learners, people welcome to explore Holocaust studies, and fellow human beings. 


\section{Preface}

This book is written to encourage all of us to learn and teach about the Holocaust. I hope it will encourage and help Holocaust educators develop our skills and insights. We continue to learn about, share, and develop engaging educational resources and curricular materials that inspire learning about the Holocaust and human rights. As colleagues, we all can help one another to make good choices in this process. We learn from each other as we learn from the past and extend chains of memory into the future. Teaching and learning about the Holocaust, genocides, and human rights, we can discover inspirational examples of resilience, including Nechama Tec, a child-survivor of the Holocaust and scholar of women in the Holocaust. Tec began 10 years of careful interviews with fellow survivors with the reasonable assumption that compassion, cooperation, and self-sacrifice were somewhat rare during times of upheaval and in contexts of oppression and coercion. She then discovered evidence to the contrary (Tec, 2003).

I hope that this text, along with many others, helps us to sustain a pedagogy of hope which supports our individual and cultural resilience. There are many good ways to learn about and from the Holocaust. Even when the truth is tragic or grim, we can humanize the Holocaust and find resilient role models. We can learn to teach about the Holocaust from a position of strength. We can find heroes in historical reflection and gain courage for the times we face powerful challenges in our own lives, even while we recognize that our world remains vulnerable to oppressive and harmful human and social forces.

Holocaust and genocide education can be challenging. As present or future Holocaust educators, and as lifelong learners ourselves, we are often challenged by detailed or distressing information. While teaching and learning about the Holocaust can and should lead to educational discussions, it requires participants who are open to interpreting difficult and complex subjects (Novis Deutsch, Perkis, \& Granot-Bein, 2018). We may hesitate to bring these difficult subjects into our educational contexts in the first place. But these challenges need not prevent or dissuade us from learning and teaching about the Holocaust, human rights, and genocide. I hope that this text helps us to affirm our responsibilities to remember past injustices and to create a brighter and enlightening future for ourselves, our students, and our coworkers. I am confident that we can and should continue to construct an ethical and responsible pedagogy of hope within Holocaust education.

We are fortunate to live in the twenty-first century. Modern and contemporary generations have learned about oppression and about genocides including the 
Holocaust as historical facts experienced by earlier generations. We appreciate that the catastrophic and destructive impact of the Holocaust (as described in Hebrew: Shoah, Kurban) has disturbed billions of people since its initiation by Nazi authorities in 1933. It was so upsetting that Theodor Adorno famously wrote that poetry was impossible after Auschwitz (Adorno \& Tiedemann, 2003). Thankfully he appears to have recanted this statement, noting that suffering has the right to expression (Horowitz, 2010).

As this catastrophe sticks in our collective memories and echoes through subsequent generations, including our own, we become reluctant witnesses to history (Stein, 2009, 2014). Nations and citizens have constructed Holocaust memorials, supported survivors, and amassed impressive scholarship on this topic. We agree that we will remember, not forget, and so we build cultural continuities, appropriate and enduring representations, and shared resilience. We do not allow the Holocaust to become obscured or lost in time. Now, with greatly improved resources for and support of Holocaust and human rights education, entryways to teaching and learning seem less like obstacles and more like entrances. Please come in and join the communities of Holocaust and human rights educators; we need you.

There are many among us, and many more new generations in our future, who have not yet found opportunities, time, or reasons to learn about the Holocaust and other genocides. Many generations will soon be arriving at the point where these topics are a part of cultural studies of world history, social studies, literature, or the arts. We can help educate all kinds of students using all kinds of materials and methods, adapting strong curricula and lesson plans that can promote dynamic and transformative educational moments. It is our privilege as educators; it is also our responsibility.

As Holocaust educators, we are fully aware that twenty-first-century learners and teachers bring a variety of important and diverse concerns and contexts for comparison to each educational process (Cowan \& Maitles, 2017). Many students and teachers around the world understand far too well the sting of past or recent prejudice, injustice, and discrimination. Microaggressions, social injustices, and enduring inequalities can and do affect our lives, our families, and our public health, making our communities sicker, less safe, less productive, and more difficult (Colen, Ramey, Cooksey, \& Williams, 2018; Williams, 2012). Racism and racial privileges are with us still, not relics of the past (Bonilla-Silva, 2014). Modern life is still and too often challenged by illegal discrimination, hate crimes, and racialized violence (United States Federal Bureau of Investigation (FBI), 2017).

While the Holocaust may appear to some distant or less relevant than other forms of persecution or genocides, we can find common understanding among our students and ourselves. We can link and compare past and present global and cosmopolitan examples of injustice, discrimination, racialization, and violence without forgetting to remember and provide particular details of the Holocaust (Levy \& Sznaider, 2006). The Holocaust was not entirely different from modern racism; antisemitic racism was enacted through Nazi law by racializing definitions of Jews and Roma (Sinti) (Bazyler, 2016). We must educate and cooperate to 
eliminate oppressive social forces across national, racial, and ethnic inequalities, in order to improve society for all cultural groups (Collins, 2016).

We believe that resilience is an important aspect of education and that challenges to educational inclusion remain (Duckworth, 2016; Goodman, 2018). As educators promoting student success, we share stories of resilience to inspire and engage one another. We illustrate our curricula and our classes with facts, statistics, and by example. In Holocaust education, and when discussing other examples of genocide, we can humanize even the most horrific statistics. We can access survival narratives and listen to surviving voices who endured genocide, thanks to digital technologies. Survivors-as-witnesses to the Holocaust and other genocides share profound truths; we need only and first to listen or read (USC Shoah Foundation, 2018). Once we read, see, or hear survival testimonies, the narrators are educational ambassadors, with human experiences carrying us into monumental historical tragedies, reinforcing historical knowledge and also a sociological imagination (Kushner, 2017; Mills, 1966). We can sometimes apply consequential lessons learned about resilience to our own lives. Holocaust education can inspire, not just shock, sadden, or evoke pity. As Holocaust educators, we can be part of this inspirational process. Yes we can-we can do this.

I myself have an unusual family history that similarly inspired me to write this text. I am a child and grandchild of Holocaust survivors. I first learned of my family experiences in the Holocaust while doing research for a family history project. I was taking a history course in a Quaker-inspired North Carolinian high school, Carolina Friends School. My father, Dr. Steven Polgar (born in Budapest, Hungary, in 1931), was a Holocaust survivor who was born of Jewish parents. He had been a refugee, educated in the United States, earning a $\mathrm{PhD}$ in anthropology at the University of Chicago. He worked as professor until his early passing in 1978. As a teen, I could not imagine or fathom the difficulties that he had faced as a young person. I did not ask him to describe or record his experiences until it was too late to do so. As an adult, I later learned some information about the historical context he endured: the Holocaust in Hungary was one tragic chapter of the Shoah, arriving late in the history of genocide in Central Europe (Vági, Csősz, \& Kádár, 2013). Along with his elder sister Vera and his parents, my father was (I learned from relatives when I was a young man) unusually fortunate to have survived "the camps."

All four of my nearest paternal relatives, along with a few of our extended family members, survived confinement in a prison camp. My father, aunt, and their parents survived a concentration camp in Bergen-Belsen, in northern Germany. Even after US President Ronald Regan visited Bergen-Belsen (Jensen, 2007), this "camp" was, in my mind, a terrible and faraway place in which I had little interest. I had a clearer view of Auschwitz, where I knew many Jewish people were murdered, and I knew that few had been as "lucky" as my paternal relatives. I also knew, as a young adult, that many survivors had immigrated to the United States. But I did not know more than one or two, outside my family. Now I know that there are entire communities of people with survivor lineages (Epstein, 1979), and I have a collection of books that teach us about the Holocaust. When I can, I ride the tumultuous tides of history that swept my paternal family across 
continents and later across the Atlantic Ocean (Bardgett \& Cesarani, 2006; Reilly, 1997). I am one of a specific type of second generation immigrant in the United States; perhaps 200,000 of us were born to more than 100,000 postwar immigrants (Stein, 2014). We share the experience that at least one of our parents was pushed out of Europe by a catastrophe and then was able to move to the United States to make a new life. We tend to be curious about our family history, but we also have less extensive kinship networks (Bukiet, 2002).

My father and his immediate (nuclear) family were all survivors and thus unusual in comparison to the majority of Jews who were sent to concentration camps during the Holocaust. As I learned from my aunt and grandmother, all four of my nearest paternal kin were released from Bergen-Belsen and taken to Geneva, Switzerland, on one of the "Kasztner trains," aided by the Red Cross in late 1944 (Bauer \& Keren, 2001; Vági et al., 2013). They were able to live as refugees in Geneva and then migrate to the United States in 1948 because my medically trained grandfather got invited to work at a medical laboratory in New Haven, Connecticut. My grandmother, Sophie Fonagy Polgar (1908-1988), was already an educated woman before her deportation from Hungary; as an immigrant to the United States, she became (in the United States) a teacher of French language at Oakwood School in Poughkeepsie, New York. She was a loving presence for all her grandchildren, becoming a widow at an early age, and working to educate everyone around her. She inspired us all; she was a resilient and caring teacher, and also a grandmother whom everyone both respected and loved.

Grandmother Sophie (we called her "Anyu") was the first to share my family's Holocaust experiences with me. Her words reinforced the fact that she was resilient and strong, not visibly sad or resentful, and she was always proud of our family and its continuity. She spoke warmly of wonderful family past, lives in Budapest, with riverside boating and comforts of urban life. She was multilingual, as were my father and aunt, a skill which aided her in their survival and careers. In addition to her native Hungarian language, Sophie taught French in the United States and English as a second language. She spoke English fluently, along with some German and Italian. She was respected and loved by all who knew her.

For Sophie F. Polgar and for her husband and children, survival meant release from Bergen-Belsen on two different and successive trains to Geneva. Her mother Frieda Fonagy had a separate experience; she was said to have hidden in a convent. We learned of a miraculous moment where, as children, my father Steven and his elder sister Vera were reunited with their parents (Sophie and Ferenc) in Geneva. A first transport (a kind of "freedom train," which I have learned since carried refugees from Bergen-Belsen to Geneva in September 1944) brought out my father and aunt. A second train in December later carried out my paternal grandparents, resulting in this wonderful moment of nuclear family reunification. Grandma Sophie gave partial credit to the (International) Red Cross for this liberation, though it appears international Jewish relief groups (including the JRC) were also involved (Favez 1999). This privilege, first release from Bergen-Belsen for "the children"” (including my father) and later for their parents, was a rare gift that shortened their persecution and led to familial 
survival. I lament that my grandfather died before I was born and my father died when I was a teen, limiting my chances of hearing his recounting of these events. Vera and Sophie shared these experiences, but they have also passed, leaving some historical questions without answers. I have reconstructed this difficult and partial family history, with help from historical materials, precious family interviews, discussions with a few relatives, and some shared recollections.

My father and his family were deprived of their property and most possessions, like most Jewish camp survivors. They were starved, shamed, and shaved. I was told by surviving kin that our family experienced painful mistreatment before, during, and after their imprisonment in the Belsen concentration camp. When released, as noted, they were reunited and then housed in a Geneva "home for intellectual refugees." They were able to slowly regain health and weight, though their lives were interrupted and forever changed. Like many others, they slowly recovered and continued life as displaced people who lived as refugees, first in Geneva and then (I think by ship from France) as migrants to the United States. As a later chapter will describe, these were difficult experiences, and these narratives were sometimes left to fade into the past, while at other times recounted as anguished memories that could upset those family members learning about their difficulties, creating burdens of memory (Langer, 1991). We carefully but rarely received these narratives from our family members, sometimes reluctant witnesses, who were perhaps protecting their kin from the harms of sometimes painful and potentially humiliating memories (Stein, 2014).

My aunt, survivor and scholar Dr. Vera John-Steiner, was the eldest, daughter of Sophie Fonagy Polgar and Ferenc Polgar, born with our family surname (Vera Polgar). She earned higher educational degrees (including a doctorate) in the United States, married and divorced, and was until very recently a respected professor of linguistics and psychology. Her life and scholarship remain influential (John-Steiner, 1985, 2000; Lake \& Connery, 2013). Vera told us that the camps were difficult and hardest for the male members of the family. She was an elder sibling who helped my father endure ongoing challenges, both during and after the Holocaust. It is still hard for me to imagine my relatives in the camps; the image of gaunt figures during and after imprisonment, which my grandfather sketched in a drawing, haunts my ideas of our family's Holocaust experiences.

Like many children of survivors, my life has been comparatively privileged, far less disrupted, and not as remarkable. I happily grew up in North Carolina as a kid whose parents had "moved south" from New York City. I attended our rural Quaker school and, while always happily identifying as Jewish, I had limited Jewish cultural education or experience of Jewish rituals. As an adult, sometime after my father had passed away, I learned that my immigrant kin had assimilated by necessity. They believed in science over religion and were resilient but not entirely unique in many respects. Like others, my paternal kin were pushed by the Holocaust into a forced relocation, what academics like to call a form of exile or diaspora, traveling among emigrant European waves toward many different shores beyond the European continent (Dwork \& Pelt, 2009).

I eventually learned that I am a "second generation" Hungarian-American and one of many children of Holocaust survivors who may also have been impacted, 
even harmed, by the lingering effects of a catastrophe (Stein, 2009, 2014). As part of modern generations who learn that our cultural identities require development and preservation, not just adaptive assimilation, I learned about and am proud of my Hungarian and Jewish heritage. The Internet and social media now allow me, among many others, to find online community with family and other people around the globe who have also experienced such complicated histories. These problems continue for many transnational families to this day.

My paternal grandfather was a Holocaust survivor named Ferenc Polgar, an assimilated Hungarian physician and radiologist who suffered greatly during and after his mistreatment in the Holocaust. Ferenc died in the 1950s when my father was still a young man, prior to my birth; we retained only limited knowledge of his life and difficult experiences. As an eldest son, my middle name is a limited but poignant memorial to his importance and survival. I was comforted to learn that fragmented families and second generation concerns were and are common in the wake of the Holocaust (Epstein, 1979). One author reflects on growing up with survivor-parents and summarizes this well: "Other people's parents had parents" (Bukiet, 2002).

I am thankful to have learned from the work of sociologist Arlene Stein (2003) that my father's silence on the subject of the Holocaust may have been protective toward. Silence in response to anguished or unheroic memories was not unusual (Langer, 1991); many other survivors remained, some for decades, relatively quiet or silent about their experiences. Some may have been trying to spare their own spouses and children from the pains of traumatic memories. After all, who can fully appreciate the suffering and difficult adjustments required by traumatic experiences, including those in concentration camps (Frankl, 1992)? In the United States and elsewhere, during the early postwar years, many Americans preferred to focus on the heroism of militaries, not the harsh worlds that harmed millions of victims (Stein, 2014). Even so, we had some comprehensive social responses during postwar periods. Good people helped and associations arose to generate a 1950s war on prejudice, aligning Jewish and Christian values, to create more inclusive society, in the wake of the Holocaust (Svonkin, 1997).

My father, among many others, heroically endured the Holocaust, along with immigration, and variable degrees of antisemitism. He chose to become an academic, worked hard as a student of cultures, became a scholar and then a teacher. While my paternal grandfather struggled with assimilation after immigration, my father became an American teacher and scholar, and thus followed the lead of his mother. My father worked in leading institutions, became a professor, and showed great respect for cultural resilience and human diversity. In April 1978, he passed far too early in life from a heart attack. I regret that he did not speak to me about his survival, but I respect his (not uncommon) decision to spare us (his children and family of choice) the terror and humiliations of the Holocaust (Stein, 2014).

I have slowly come to realize that my father and aunt were not just impressively academic family elders but a sort of unexpected global representatives. They were in a generation of refugee-survivors who came to the United States, having experienced the same European catastrophe as Anne Frank (also a teen 
who was imprisoned at Bergen-Belsen, though later during the Holocaust), and of the same nationality as Elie Wiesel, author and Nobel Prize winner, a fellowHungarian survivor. It is not surprising to me now that my aunt became a professor of linguistics and psychology. My father became a student and teacher of human cultures, an anthropologist, and he worked cross-culturally with many different groups, including Native Americans and West Africans. Both were more secular than religious, for different reasons, and both participated in multicultural education and multicultural research, along with gender studies, before such topics were widely understood or even accepted in their academic circles. Now, I am blessed to learn more fully about the Holocaust from the many organizations that preserve Holocaust memory for us all. I hope you can and will join me in this process.

I've researched and written this book in part as a tribute to my family members who survived the Holocaust. I should also note that my late mother, Dr. Sylvia K. Polgar, was herself a resilient woman, and I never forget that I owe her my life. I was relatively slow to arrive to my present responsibilities that I consider part of a post-Shoah procession which I now understand as a chain of Holocaust memory. I am honored to have the chance to share my family history and other insights with you as readers. I owe my own Holocaust education to the memories of my father and his sister, and especially to my grandmother ("Anyu") Sophie F. Polgar. I am proud to recall that she expressed great joy in many aspects of life and that I never heard her digress into anger or self-pity, even after all that she (and her family) had endured.

Sophie Polgar's description of her Holocaust survival remains my founding model of resilience and caring. I will never forget what she told me as a teen: she helped others in her barrack; she offered dignity and respect to her elders during the ordeal, and she continued as a caregiver for her disabled mother (Frieda Fonagy) for years after her survival and immigration to the United States. Her compassion for others was emulated and continued by her children, my father Steven Polgar and my Aunt Vera (born Polgar) John-Steiner. Resilience and human compassion are the themes in this text that I learned from my family members. Subsequent chapters will elaborate this theme. I hope that you too, kind readers, will find examples and models of such qualities in your work as Holocaust educators.

I owe a special thanks to Dr. Vera John-Steiner, my paternal aunt, who helped our family endure many challenges, aiding my father when they were refugees in Europe and when new to the United States, and later helping those of us in our second generation to endure more modern challenges. Like her mother Sophie, Vera John-Steiner was an inspiring teacher and a scholar (Lake \& Connery, 2013), a resilient and caring role model to many, collaborating and helping us appreciate collaboration well beyond our extended families (John-Steiner, 2000). Vera was a humanist who passed away while I was writing this book, a psychologist and linguist whose books and writings on linguistics and collaboration show us the best of human and social capacities. She provides inspiration through observation, much like her fellow scholar Patricia Carini, both associated with Columbia Teacher's College. Thanks to scholars like Dr. John-Steiner, 
Dr. Sondra Perl, and Patricia Carini, we continue to learn that respect for others is both the center and the driving force of our educational work. We cannot practice a pedagogy of hope without writing, including, and teaching about all people, first and foremost.

Dr. Arlene Stein's work Reluctant Witness also inspired me to write this book (Stein, 2014). Stein reminds us that there were roughly 125,000 European Holocaust survivors who immigrated to the United States after the war. As Stein shares her work, including such simple demographic insights, many of us feel that our complex lives have good company. We, as children of refugees and immigrants, are truly privileged to be part of the United States (Alba \& Foner, 2015; Kasinitz, 2008). We in the second generation who are children of Holocaust survivors, comprise about 250,000 people in the United States. We each have unique and important lives and stories to share and compare.

Good ideas about any subject begin with inspiration, hope, and respect for humanity. Certain types of scholarship should add to compassion for our subjects and for one another. Both scholarship and education can show that we are all valued as human beings, regardless of our demographics, affiliations, or statistical profiles (Carini, 2001). Education and scholarship is for people, not just about people; this is a critical lesson that I have learned from the women and teachers in my family: my mother Dr. Sylvia K. Polgar, my grandmother Sophie F. Polgar, and my aunt Dr. Vera John-Steiner. I see their work and lives as an enduring form of support for human dignity; we are lucky that strong women grace our lives and our families.

I have other kin who are engaged in the process of creating culture and preserving memory. My cousin Dr. Suki John is a leader in this respect; she works and inspires as a dance professor and choreographer. My brother Christopher Polgar reminds us that we can reflect on our own Jewish cultural traditions just as well as we can reflect on others. My cousin Sandor John works to improve life for immigrants still, and this reinforces a point shared by Dr. Martin Luther King in his final speech in 1968: All work has dignity (King \& Honey, 2011; Miller, 2012). Likewise, every person who survives violence or catastrophe is an inspiration to us all. Thank you for helping us dignify these inspirational experiences through Holocaust and human rights education. Perpetrators were found responsible for the horrific and criminal injustices of the Holocaust (Bazyler, 2016); we now find ourselves responsible to carry lessons of the Holocaust forward to improve future generations. 